\title{
Evaluation of the State-Wide Implementation of an Allied Health Workforce Redesign System: Utilisation of the Calderdale Framework
}

TILLEY PAIN; SARAH PATTERSON; PIM KUIPERS; PETREA CORNWELL

Tilley Pain - Townsville Hospital and Health Service - Allied Health Governance Office, Queensland, Australia Sarah Patterson - Metro South Hospital and Health Service - Logan Central Community Health Centre Woolloongabba, Queensland, Australia Pim Kuipers and Petrea Cornwell - Griffith University, Queensland, Australia

Correspondence: tilley.pain@health.qld.gov.au

\section{ABSTRACT}

Background: Increasing demand for allied health services is driving workforce redesign towards greater productivity within budgetary constraints. To date, there has been limited research into workforce redesign tools at an organisational level. The aim of this article was to evaluate an implementation of The Calderdale Framework for state-wide service delivery workforce redesign within allied health settings across Queensland.

Method: A multi-phase methodology with mixed methods of data collection was used. This included analysis of documents, staff surveys, and semi-structured, in-depth interviews with staff from work units utilising the Framework across the state.

Findings: The primary mechanisms for implementation were staff training and provision of centralised resources. Across the state, all health services engaged in training and most completed associated workforce redesign projects. However, the number and type of projects varied across the state as did the successful projects. Feedback from staff indicated the structured nature of the framework was viewed positively, but was time intensive to perform. Local contextual factors heavily influenced workforce redesign success.

Conclusion Key factors pertaining to statewide workforce redesign include: providing coordinated and centralised systems to support staff, ensuring adequate training, prioritising the development of key local staff, and proactively managing local contextual factors.

Keywords: allied health, workforce redesign, evaluation 


\section{INTRODUCTION}

Allied health professionals are key service providers within Australian health care settings. As with other providers, they face numerous challenges to respond to current and future health care needs. Issues such as ageing populations, increased rates of long term chronic illness, higher consumer expectations, increasingly complex treatment technologies, and the pressure to maintain safety and quality are widely reported.[1] Such challenges necessitate more streamlined processes, a more flexible workforce, and greater productivity (while improving quality and managing budgetary constraints).[2] Allied health managers and policy makers may respond by identifying strategies to maximise impact and effectiveness of allied health professionals and their practice.

Promising strategies to maximise the flexibility of the allied health workforce include, delegation of tasks to therapy assistants, [3] and sharing of tasks between different allied health professions. [4] However, implementing these strategies is challenging for numerous reasons, including limited staff engagement, the absence of frameworks and insufficient guidelines. [5]

Examples of service or workforce redesign exist, although the broader implications of implementing them are rarely presented or explored. [6] This is surprising, given the substantial financial, human and organisational resources involved to implement the changes. [6] Despite inclusion of successful contextual factors for change (e.g. effective leadership, meaningful evaluation and attention to the organisational and the cultural context), [6] many workforce redesign initiatives were not sustained. Therefore, sustainable change may require a comprehensive framework with clear and specific strategies.

The Calderdale Framework (CF) may be such a framework. CF is a tool to facilitate safe and effective workforce redesign within multidisciplinary teams. [1] It is a seven-step, clinician-led process, used to improve the way a healthcare team works with specific focus on planning and implementing therapy assistant roles and/or inter-professional skill sharing. [1] CF provides a mechanism for workforce redesign through a formal, risk managed and structured framework. It includes systematic methods for service and task analysis, to assist in developing new roles, identifying new ways of working, and facilitating service redesign. CF is underpinned by three levels of training: Foundation, Facilitator and Practitioner; each reflecting increasing levels of expertise.

CF was chosen by the Allied Health Professions' Office of Queensland (AHPOQ) to facilitate workforce redesign for new models of care. CF was offered to all 16 Hospital and Health Services (HHS) across the state with the opportunity to opt-in to have their staff trained and/or to have CF projects implemented within their services. The aim was for statewide coordination, including support networks, sharing of resources, and training, leading to standardisation of workforce redesign across the state.

\section{Aims and objectives}

The aim of this study was to evaluate the implementation of CF across Queensland Health between 2011 and 2015 by documenting the context and mechanisms of implementation as well as the associated outputs, at both a state-wide and HHS level. Specific questions to be addressed were: 1) Is 
CF fit for purpose as a tool for workforce redesign and reform; 2) Does training and workforce development processes support implementation of the CF; and 3) Are the support systems and processes (e.g. documents and resources, coordination/communication) appropriate for state-wide and local implementation of CF?

\section{METHODS}

\section{Methodology}

This evaluation was conducted between July 2015 and April 2016. The evaluation was commissioned by AHPOQ via a competitive process to: assess the performance of $\mathrm{CF}$ structure and approach as an enabler of local workforce re-design; and guide decisions by AHPOQ about continuation or amendments to state-wide implementation. Governance of the evaluation included oversight by the Chief Allied Health Officer or Project Lead, the establishment of a steering committee of Directors of Allied Health in participating HHSs.

The evaluation was based on the concept from realist evaluation [7] to understand what causes change. The evaluation was a retrospective examination of the initial CF implementation in Queensland from 2011 2015 and used a multi-phase, mixed methodology for data collection. Methods included: an email survey of CF-trained staff, qualitative analysis of training documents, and semi-structured, in-depth interviews with AHPOQ staff, CF-trained staff, and clinicians and managers from work units using CF.

Insights into the mechanisms of CF implementation across Queensland Health were obtained through review of key documents, and via interviews with $\mathrm{AHPOQ}$ staff. The process of CF implementation, including training, coordination, network management, and the provision of support was documented. State-wide contextual factors and outputs were noted alongside CF training and project completion across the dispersed HHSs from AHPOQ records and survey outcomes.

In-depth interviews were conducted using a purposive sample of relevant stakeholders to explore local mechanisms, contextual factors and outputs of $\mathrm{CF}$ implementation across the state. In total, 18 interviews were completed from eight HHSs as shown in Table 1. Interviews were conducted with six facilitators, five managers, four clinicians and three practitioners.

Each interview focussed on local CF projects including discussion of the aims, outcomes, barriers and strategies. Interview questions explored components of the framework as a workforce redesign tool. The interviews were completed and recorded by the project officers, ranging from thirty minutes to one hour. Participants were provided with a unique code to reflect their involvement with the various $\mathrm{CF}$ projects. These included CFTS for $\mathrm{CF}$ trained staff (both facilitators and practitioners), CFMA for managers of CF projects and $\mathrm{CFCL}$ for clinicians without formalised training who participated in a CF project. Interviews were transcribed verbatim for thematic analysis. 
Table 1 - Qualitative interview participants sample

\begin{tabular}{cccccc}
\hline HHS & Context & Practitioner & Facilitator & Clinician & Manager \\
\hline 1 & Community & & $\sqrt{ }$ & $\sqrt{ }$ & $\sqrt{ }$ \\
\hline 2 & Hospital & & $\sqrt{ }$ & $\sqrt{ }$ & $\sqrt{ }$ \\
\hline 3 & $\begin{array}{c}\text { Subacute } \\
\text { Rehabilitation }\end{array}$ & & $\sqrt{ }$ & $\sqrt{ }$ & $\sqrt{ }$ \\
& $\begin{array}{c}\text { Inpatients / } \\
\text { Outpatients }\end{array}$ & & $\sqrt{ }$ & $\sqrt{ }$ & \\
\hline 4 & Hospital & $\sqrt{ }$ & $\sqrt{ }$ & & $\sqrt{ }$ \\
\hline 5 & Community & & $\sqrt{ }$ & & \\
\hline 6 & HHS-wide & $\sqrt{ }$ & & & \\
\hline 8 & HHS-wide & $\sqrt{ }$ & & & \\
\hline
\end{tabular}

An online survey of $36 \mathrm{CF}$ facilitators across the state identified factors relevant to local CF projects. Survey questions included:

- Project location, aims and focus

- Project dates and information about early cessation

- Funding received

- Average time spent on implementation

- Outputs, outcomes, service delivery changes implemented or anticipated

- Sustainability of workforce changes over time

Survey data and training databases were analysed using frequency counts. Qualitative data was analysed thematically by two members of the evaluation team (SP and a research assistant) using NVivo Software to code and categorise data. Initially, SP (a trained CF Facilitator) and the research assistant examined one of the transcripts together to code key concepts from interviews and establish agreement on the coding process. Next, several transcripts were coded separately, then reviewed together to ensure consistency of coding practice. The project officer (SP) examined the remaining transcripts using the agreed processes. Finally, the project officer and research assistant discussed the codes, grouped data into categories and formed the main themes across the interviews. SP's CF experience allowed the analysis to be completed within context, while the research assistant was new to the framework providing independence in coding.

\section{Ethical approval for the study}

Approval was granted by The Prince Charles Hospital Research, Human Research Ethics and Governance Unit (HREC/15/QPCH/227) on 26th August 2015. The opt out process allowed Directors of Allied Health across the state to exempt their HHS from the project. No HHS refused to participate 


\section{RESULTS}

\section{Mechanisms for CF Implementation}

The primary mechanism for state-wide implementation of CF was training. Initial training at Foundation and Facilitator level was provided to 53 and 22 staff respectively by Effective Workforce Solutions (CF license holders) in 2011 and three staff were provided the advanced Practitioner level training. Newly trained Practitioners provided ongoing Facilitator training and subsequent Foundation level training was provided by in-house $\mathrm{CF}$ Practitioners or Facilitators within the HHSs. Two CF Practitioners allocated a proportion of their time to CF implementation supported by their HHS and the other CF Practitioner was an AHPOQ staff member with allocated time to support implementation. Table 2 contains details of staff training by year. Interest in CF Foundation and Facilitator training was sustained over the data analysis period with course completion rates improving over time.

Table 2 - CF staff training numbers by year

\begin{tabular}{|c|c|c|c|c|c|}
\hline & \multirow[b]{2}{*}{$\begin{array}{l}\text { Number of } \\
\text { staff that } \\
\text { completed } \\
\text { CF } \\
\text { Foundation } \\
\text { Training }\end{array}$} & \multicolumn{3}{|c|}{ CF Facilitator Training } & \multirow[b]{2}{*}{$\begin{array}{l}\text { Number of } \\
\text { staff that } \\
\text { completed } \\
\text { Practitioner } \\
\text { Training }\end{array}$} \\
\hline & & $\begin{array}{l}\text { Number of } \\
\text { staff that } \\
\text { completed } \\
\text { CF } \\
\text { Facilitator } \\
\text { Training }\end{array}$ & $\begin{array}{l}\text { Number of } \\
\text { staff that } \\
\text { commenced } \\
\text { but did not } \\
\text { complete CF } \\
\text { Facilitator } \\
\text { Training }\end{array}$ & $\begin{array}{l}\text { Number of } \\
\text { staff still } \\
\text { completing } \\
\text { CF training } \\
\text { at time of } \\
\text { review }\end{array}$ & \\
\hline 2011 & 53 & 8 & 14 & - & 2 \\
\hline 2012 & 22 & 6 & 4 & - & - \\
\hline 2013 & 20 & 5 & 3 & - & 1 \\
\hline 2014 & 37 & - & - & 22 & - \\
\hline 2015 & 40 & - & - & 9 & - \\
\hline Totals: & 172 & 19 & 21 & 31 & 3 \\
\hline
\end{tabular}

The secondary mechanism of CF implementation was the establishment of a centralised system for monitoring $\mathrm{CF}$, sharing resources, training coordination, and peer support. These systems were: 
- Coordination, administration and review of the CF Facilitator training.

- Coordination of the development and validation of clinical task instructions (CTIs) plus their publishing and distribution.

- Production of information sheets and guidelines.

- Establishment of the CF Facilitator support network.

- Managing communication and CF enquiries.

Qualitative data demonstrated the centralised support provided by AHPOQ was integral for projects at local levels. Interviewees also acknowledged the value of the state-wide CF facilitator network during their projects. Some HHSs also established local CF Facilitator networks, if sufficient Facilitators, to share ideas and provide peer support. Respondents discussed the benefit of shared resources, e.g. local / draft clinical task instructions (CTIS) and training packages, through the shared network drive with many using existing CTIs for their local projects. Pre-existing CTIs were invaluable because they reduced implementation time and burden on clinical staff. An example statement was: 'We've got numerous CTIs, either formalised or in development or being used in HHS, that we can draw on because we've got the network' (CFTS9)

Staff conducting local projects found CF a structured workforce tool to provide practical steps to follow throughout implementation. Interviewees reported the framework, as well as the associated tools, guided challenging conversations about professional roles and boundaries. An example statement was: 'I actually see that The Calderdale provides the framework that actually supports that conversation, because l've seen that conversation outside of a Calderdale framework and it is messy'. (CFMA5)

The time required to implement the CF process was a significant challenge reported by staff. Service redesign through the seven stages of CF was highly structured and detailed, which meant attending to every detail took considerable time. An example statement was: 'I feel like quite a raw process because we've had to go back to basics and look at all the different aspects of clinical care that we need to make sure that everyone's aware of because it hasn't been done before. So that in itself has been a big task' (CFCL2).

Direct and indirect CF activities were necessary, but time-intensive. The direct workload of implementing CF itself was timeintensive but additional time was required for arranging meetings, aligning diaries for staff to attend CF-related meetings, and building staff engagement in the CF process. An example statement was: 'It's been really challenging I think, to routinely be able to set aside the time' (CFTS7).

Formal project and evaluation plans were key success factors of CF implementation. Project plans that included details regarding governance, time lines, anticipated outcomes, facilitator roles and team expectations were considered superior. Evaluation plan was considered important to establish credibility and clear outcomes: 'So the evaluation was important all the way through mostly for the credibility and reporting side but also just to monitor how things were going.' (CFTS2). Interviewees commented that CF did not equip 
clinicians with skills for project management and evaluation (such as managing difficult conversations and managing change), and may have reduced project completion rates.

\section{Context}

CF training across the state is shown in Table 3. All HHS had at least one staff member attend Foundation training, 15 of the 16 HHSs had staff attend Facilitator training and two HHS had CF Practitioners. The third CF Practitioner was an AHPOQ staff member. All CF Practitioners were employed in unrelated roles, meaning CF activities were performed in addition to their substantive role.

The state-wide organisational restructure was the primary contextual barrier identified by staff during interviews. Queensland Health was decentralising to a regional HHS structure during the time CF was implemented across the state. This restructuring was perceived to confounded engagement in CF by 'changeweary staff' resulting in a negative impact on CF implementation and project completion rates. Two example statements were: 'We've since had more restructure and operational reporting lines for the game changed and so, you know, a few complexities around all of that. (CFTS7)'; 'The biggest problem is that we're asking people to change and the very change weary and change wary involvement. I'm asking people to just change one more thing. At the moment in Queensland that is a very big ask.' (CFMA1)

Two additional contextual barriers to local engagement in CF were identified from the interviews. First, high turnover of staff and numerous others on parental, or other leave meant continual orientation and awarenessraising for new staff was required to maintain staff engagement. Many new staff were in acting positions. An example statement was: 'It's all very well and good, we might do this and put some time into training someone but they might then leave and then we start all over again, and how do we manage the workload of the team that's associated with that.'(CFTS5). Second, defensiveness around specialist positions, teams and roles was identified. Staff raised concerns that dilution of professional autonomy and identity may occur with skill sharing. An example statement was: 'But that was the team being very rigid and wanting to be perceived as a high specialist team. So, they were more difficult to get to embrace the skill sharing.' (CFTS1).

The number and location of CF projects across the state is shown in Table 4. Most HHSs commenced one or two projects, and HHS with higher numbers of CF trained staff tended to initiate a greater number of projects. 
Table 3 - Calderdale Framework training outputs by HHS / Division (Oct 2011 - Nov 2015)

\begin{tabular}{|c|c|c|c|c|c|c|c|c|c|c|}
\hline \multirow{2}{*}{$\begin{array}{l}\text { HHS / } \\
\text { Division }\end{array}$} & \multirow{2}{*}{$\begin{array}{l}\text { Calderdale } \\
\text { Framework } \\
\text { Practitioner } \\
\underline{\mathbf{S}}\end{array}$} & \multirow{2}{*}{$\begin{array}{l}\text { Foundation } \\
\text { workshop } \\
\text { participants }\end{array}$} & \multicolumn{8}{|c|}{ Facilitator training program } \\
\hline & & & ن & 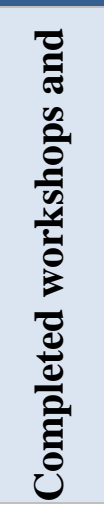 & 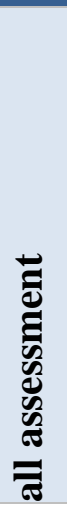 & 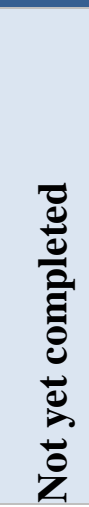 & 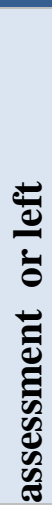 & 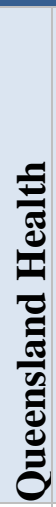 & 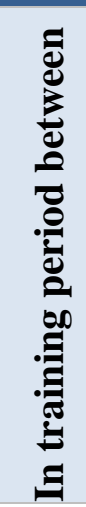 & $\begin{array}{l}\frac{n}{0} \\
\frac{2}{5} \\
\frac{1}{2} \\
\frac{1}{0} \\
\frac{1}{3}\end{array}$ \\
\hline HHS-1 & & 2 & 3 & 0 & & 1 & & & 2 & \\
\hline HHS-2 & & 20 & 5 & 1 & & 1 & & & 3 & \\
\hline HHS-3 & & 12 & 6 & 2 & & 1 & & & 3 & \\
\hline HHS-4 & & 1 & 2 & 0 & & 2 & & & 0 & \\
\hline HHS-5 & 1 & 23 & 5 & 2 & & 0 & & & 3 & \\
\hline HHS-6 & & 8 & 3 & 1 & & 1 & & & 1 & \\
\hline HHS-7 & & 1 & 0 & 0 & & 0 & & & 0 & \\
\hline HHS-8 & & 1 & 2 & 0 & & 1 & & & 1 & \\
\hline HHS-9 & & 1 & 4 & 1 & & 1 & & & 2 & \\
\hline HHS-10 & 1 & 47 & 10 & 5 & & 0 & & & 5 & \\
\hline HHS-11 & & 23 & 11 & 2 & & 5 & & & 4 & \\
\hline HHS-12 & & 3 & 4 & 2 & & 1 & & & 1 & \\
\hline HHS-13 & & 5 & 6 & 2 & & 3 & & & 1 & \\
\hline HHS-14 & & 4 & 4 & 1 & & 0 & & & 3 & \\
\hline HHS-15 & & 14 & 2 & 0 & & 1 & & & 1 & \\
\hline HHS-16 & & 7 & 3 & 0 & & 2 & & & 1 & \\
\hline AHPOQ & 1 & 0 & 0 & 0 & & 1 & & & 0 & \\
\hline Totals & 3 & 172 & 71 & 19 & & 21 & & & 31 & \\
\hline
\end{tabular}


Table 4 - Calderdale Framework projects reported by HHS (Oct 2011 - Nov 2015)

\begin{tabular}{|c|c|c|c|c|c|}
\hline HHS / Division & $\begin{array}{l}\text { Total } \\
\text { number of } \\
\text { Facilitators / } \\
\text { Practitioner } \\
\text { s (who } \\
\text { commenced } \\
\text { training) }\end{array}$ & $\begin{array}{l}\text { Total } \\
\text { Calderdale } \\
\text { Framework } \\
\text { Projects } \\
\text { Implemente } \\
\text { d }\end{array}$ & $\begin{array}{l}\text { Complete } \\
\text { d } \\
\text { Calderdal } \\
\text { e } \\
\text { Framewor } \\
\text { k Projects }\end{array}$ & $\begin{array}{l}\text { Ceased } \\
\text { Calderdal } \\
\text { e } \\
\text { Framewor } \\
\text { k Projects }\end{array}$ & $\begin{array}{l}\text { Ongoing } \\
\text { Calderdale } \\
\text { Framewor } \\
\text { k Projects }\end{array}$ \\
\hline HHS-1 & 3 & 2 & 0 & 1 & 1 \\
\hline HHS-2 & 5 & 3 & 1 & 2 & 0 \\
\hline HHS-3 & 6 & 2 & 2 & 0 & 0 \\
\hline HHS-4 & 2 & 1 & 0 & 1 & 0 \\
\hline HHS-5 & 6 & 6 & 3 & 0 & 3 \\
\hline HHS-6 & 3 & 2 & 1 & 1 & 0 \\
\hline HHS-7 & 0 & 0 & 0 & 0 & 0 \\
\hline HHS-8 & 2 & 3 & 1 & 0 & 2 \\
\hline HHS-9 & 4 & 1 & 0 & 1 & 0 \\
\hline HHS-10 & 11 & 10 & 4 & 1 & 5 \\
\hline HHS-11 & 11 & 6 & 2 & 4 & 0 \\
\hline HHS-12 & 4 & 1 & 0 & 1 & 0 \\
\hline HHS-13 & 6 & 2 & 1 & 0 & 1 \\
\hline HHS-14 & 4 & 1 & 0 & 1 & 0 \\
\hline HHS-15 & 2 & 1 & 0 & 0 & 1 \\
\hline HHS-16 & 3 & 2 & 0 & 1 & 1 \\
\hline AHPOQ & 1 & \multicolumn{4}{|c|}{$\begin{array}{l}\text { AHPOQ Practitioner's projects were reported in HHS- } \\
1 \text { (1), HHS-2 (1) and HHS-7 (1) HHS data }\end{array}$} \\
\hline TOTAL & 74 & 43 & 15 & 14 & 14 \\
\hline
\end{tabular}


Structured workplace processes associated with CF were perceived as positive outcomes. Interviewees noted there was a benefit from a sense of confirmation brought about by the $\mathrm{CF}$ processes. An example statement was: 'It was just nice to kind of have it in writing, to know that you're doing the right thing and that somebody else had ticked you off and that sort of thing' (CFCL1).

Interviewees discussed improved efficiencies, such as reduced length of stay and fewer hospital readmissions resulting from their projects. Greater efficiency was reported in the survey. An example statement is: 'I think is the outcome that's the most valuable in terms of efficiency, that any part of that Calderdale framework frees the clinician up to do tasks that can't be delegable and to do the things that they should be doing and tasks that can be delegated can be delegated to someone who was more appropriate. So, for me it's always the efficiency' (CFMA3).

Improved staff satisfaction and enhanced skills and abilities were reported as benefits of CF implementation. 'And they also felt that it enhanced their own skills, they felt a lot better, you know, to be able to deliver more to patients and that it wasn't really cumbersome or burdensome doing that.' (CFTS1).

Qualitative data revealed two additional outcomes which were not primary outcomes of CF. They were: improved team dynamics; and a cultural shift towards greater acceptance of skill sharing and delegation practices. The cultural change manifest as a greater understanding, awareness and acceptance of skill sharing and delegation. An example statement was 'But really it was a culture change for the staff of how they're going to work' (CFMA4). An improved understanding of other professional roles within the team, and increased communication between allied health staff and improved teamwork was reported. For example: 'They really felt that they were having a lot more team awareness, a lot of more open lines of communication.' (CFTS6)

\section{DISCUSSION}

This evaluation explored the mechanism, context and outcomes of CF implementation in Queensland Health. It is the first evaluation of implementation of CF at a state-wide level. The intent of introducing CF in Queensland Health was to provide a framework for workforce projects to enhance allied health service delivery. The findings suggest state-wide coordinated training as a primary mechanism to implement CF was successful, as was the establishment of centralised support systems. Despite consistent uptake of training, contextual factors such as organisational restructure challenged local implementation. CF was perceived as a strong facilitator of workforce change.

A key mechanism of implementation was training by CF Practitioners to build capacity, and maintain sustainability. This mechanism agrees with the literature regarding systembased workforce redesign. [6] The central organisation of capacity building and training allowed Facilitators to be trained in all but one HHS. Ongoing interest in CF training remains strong with numerous staff commencing $\mathrm{CF}$ training in recent cohorts and continuing to enrol since the completion of this evaluation. The number of facilitators trained, or in training, suggests substantial 'change 
commitment' by the individual HHSs. Change commitment is an indicator of organisational readiness for change and leads to a collective capability to change. [8] The centralised systems and resources provided by AHPOQ endorses the work of McGrath and colleagues [9] who noted that clinical redesign processes can successfully scale up to a state-wide approach with due attention to careful planning and centralised systems.

Some external contextual factors were possibly a barrier to consistent implementation of $\mathrm{CF}$ across the state. During implementation, Queensland Health was administratively devolving to newly established regional HHSs. The devolvement caused significant service delivery changes as individual HHSs developed their own priorities. Some HHS also experienced significant structural changes leading to 'change weary' staff. Devolvement was a barrier to project completion because of less time, ability and staff motivation to participate in CF projects. Devolvement may have contributed to the proportionately lower completion rates of Foundation and Facilitator training from early cohorts compared with later cohorts.

Various internal contextual factors contributed to inconsistency of CF implementation across the state with projects in some areas flourishing and others struggling. Key staff in individual HHSs where CF workforce change was achieved, seemingly had considerable influence over the uptake of training and implementation. Therefore this 'top down' support at a local level, combined with a groundswell of newly trained CF staff resulted in a blended 'top down-bottom up' approach which facilitated completion of CF projects. [5] Potentially, key staff used local knowledge and personal relationships to enable project 'buyin' by clinicians involved with the workforce change project in turn providing mentoring and support to build capacity building in regional or rural areas. [10] In addition, key local staff in some of the regional and rural HHSs may have close working relationships with executive management providing top down assistance with project support and commitment.

There were common challenges to overcome in all HHS regardless of whether they flourished or struggled. These challenges included staff retention / turn-over, staff attitudes, and the time intensive nature of CF. The perception was that the detailed structure of CF was an enabler, but following the seven steps was a barrier due to extensive time requirements. The time commitment may have contributed to the low project completion rate. Fifteen projects were completed, plus several ongoing projects at time of review. Outcomes of completed projects have resulted in workforce redesign as expected by the framework developers. [1] Maintaining staff engagement along the timeconsuming redesign process was very difficult suggesting possession of project management skills to overcome this challenge will be required in the future. 


\section{LIMITATIONS OF THE STUDEY}

The data for this summative evaluation were collected through interviews and surveys with relevant allied health staff. This study was sponsored by the Allied Health Professions Office of Queensland and so perspectives from medicine and nursing were not included and may be a limitation of this study. Future research would benefit from including medicine and nursing to determine if CF was appropriate for health service workforce redesign.

\section{CONCLUSION}

State-wide implementation of workforce redesign frameworks such as CF require centralised systems supporting clinicians to develop CF skills, development of key local staff, and the proactive management of local contextual factors. Successful projects were associated with 'bottom-up' processes, which emphasised staff engagement, and local management support. Despite limited ability

\section{References}

1. Smith, R. and J. Duffy, Developing a competent and flexible workforce using the Calderdale Framework. International Journal of Therapy and Rehabilitation 2010. 17: p. 254-262.

2. Nancarrow, S., Dynamic role boundaries in intermediate care services. Journal of Interprofessional Care, 2004. 18(141-151).

3. Nancarrow, S., et al., Assessing the implementation process and outcomes of newly introduced assistant roles: a qualitative study to examine the utility of the Calderdate Framework as an appraisal tool. Journal of Multidisciplinary Healthcare, 2012. 5: p. 307-317.

4. Gilmore, L., et al., Skills escalator in allied health: a time for reflection and refocus. Journal of Health care Leadership, 2011. 3: p. 53-58.

5. Nancarrow, S., et al., Implementing large-scale workforce change: learing from 55 pilot sites of allied health workforce redesign in Queensland, Australia. Human Resources for Health, 2013. 11(66): p. 1-14. to make firm conclusions from the outputs arising from state-wide implementation of CF, staff consistently reported positive changes in workplace dynamics.

\section{Acknowledgements}

The authors would like to acknowledge staff from Queensland Health for their support of this evaluation, including CF trained staff, local CF project managers and the Allied Health Professions' of Queensland

\section{Declarations of Interest}

All authors are employees of Queensland Health. SP has completed CF Facilitator Training and has published research associated with her local CF project implementation.

\section{Funding}

Funding for the evaluation was provided by the Queensland Health Allied Health Professions' of Queensland (AHPOQ).

6. Melder, A., Redesign and innovation in hospitals: foundations to making it happen. 2015, La Trobe University.

7. Pawson, R. and N. Tilley, Realistic evaluation. 1997: Sage.

8. Weiner, B., A theory of organizational readiness for change. Implementation Science, 2009. 4(67): p. 1-9.

9. McGrath, K., et al., Implementing and sustaining transformational change in health care: lessons learnt about clinical process redesign. Medical Journal of Australia, 2008. 188(6): p. S32-S35.

10. Pain, T., et al., Comparison of research experience and support needs of rural versus regional allied health professionals. Australian Journal of Rural Health, 2015. 23: p. 277-285. 
Table 5 - Calderdale Framework projects 2011 - 2015: reported outcomes

\begin{tabular}{|c|c|c|}
\hline Outcome & $\begin{array}{l}\text { Number of } \\
\text { projects with } \\
\text { this reported } \\
\text { outcome }\end{array}$ & Outcome summary across Calderdale Framework projects \\
\hline $\begin{array}{l}\text { Change in waitlist } \\
\text { times }\end{array}$ & 4 & Majority reported decrease in waitlist times \\
\hline $\begin{array}{l}\text { Changes in } \\
\text { occasions of service } \\
\text { (including } \\
\text { new:review) }\end{array}$ & 5 & $\begin{array}{l}\text { Various changes in occasion of service (OOS) reported across } \\
\text { projects including - } \\
\text { reduced number of speech pathology inpatient reviews } \\
\text { reduced OOS in allied health outpatient department } \\
\text { statistically significant increase in \% new OOS for Physiotherapy } \\
\text { and Occupational Therapy staff } \\
\text { increased number of allied health referrals } \\
\text { increased number of client appointments within same client cost }\end{array}$ \\
\hline $\begin{array}{l}\text { Changes in task or } \\
\text { time and motion } \\
\text { (e.g. audit of tasks } \\
\text { or time allocated to } \\
\text { specific tasks) }\end{array}$ & 1 & An increased use of existing therapy assistant reported. \\
\hline $\begin{array}{l}\text { Change in health } \\
\text { care costs / } \\
\text { resource use } \\
\text { (excluding travel) }\end{array}$ & 1 & $\begin{array}{l}\text { Improved efficiencies were noted with reduced costs per client } \\
\text { appointment noted with an associated increased number of } \\
\text { client appointment within a fixed budget constraint. }\end{array}$ \\
\hline $\begin{array}{l}\text { Change in staff role } \\
\text { changes }\end{array}$ & 7 & $\begin{array}{l}\text { Majority reported embedding trans-professional practices within } \\
\text { allied health services } \\
\text { A few reported an increase in delegation to supporting staff. }\end{array}$ \\
\hline $\begin{array}{l}\text { Change in clinical } \\
\text { outcomes }\end{array}$ & 2 & $\begin{array}{l}\text { A video-conference-delivered, and assistant-supported falls and } \\
\text { balance group showed similar outcomes to traditional therapy } \\
\text { models. } \\
\text { Another project reported that there was no significant } \\
\text { difference in clinical outcome between skill sharing and } \\
\text { conventional uni-professional practice in a community based } \\
\text { elderly population }\end{array}$ \\
\hline $\begin{array}{l}\text { Changes in staff } \\
\text { satisfaction / } \\
\text { feedback }\end{array}$ & 9 & $\begin{array}{l}\text { About half the projects reported a general staff satisfaction } \\
\text { associated with the new models of care associated with } \\
\text { Calderdale Framework implementation, } \\
\text { A few specifically reported that Calderdale Framework improved } \\
\text { teamwork, communication and understanding of each other's } \\
\text { roles, } \\
\text { A few projects reported staff satisfaction as indicated by their } \\
\text { commitment to the new models of care and their confidence to } \\
\text { carry out their new roles within these systems. }\end{array}$ \\
\hline $\begin{array}{l}\text { Changes in client } \\
\text { satisfaction / } \\
\text { feedback }\end{array}$ & 3 & $\begin{array}{l}\text { A few projects reported a high client satisfaction regarding the } \\
\text { new allied health services, } \\
\text { One project reported more specifically that clients experienced } \\
\text { improved services and access to care post Calderdale } \\
\text { Framework implementation. }\end{array}$ \\
\hline Length of stay & 1 & $\begin{array}{l}\text { One project achieved comparable outcomes in length of stay } \\
\text { between clients admitted on weekends compared with those } \\
\text { admitted on weekdays. }\end{array}$ \\
\hline
\end{tabular}

